Peer-Reviewed Reflection

ISSN: 2162-3104 Print/ ISSN: 2166-3750 Online

Volume 6, Issue 2 (2016), 632-343

(C) Journal of International Students

http://jistudents.org/

\title{
Communication Education and International Audiences: Reflections on Instructional Challenges and Pedagogical Strategy
}

\author{
Heather Campbell \\ Bellarmine University (US) \\ Michael G. Strawser \\ Bellarmine University (US) \\ Stephen George \\ University of North Texas (US)
}

\begin{abstract}
As the movement toward international education continues, institutions must be proficient when reaching and teaching international students. Instructors should engage unique learning styles, address individual student needs, and take part in additional training to effectively teach international student learners. These instructional imperatives are especially important in communicationrelated classes, like public speaking or composition. Throughout this reflection we briefly address the current landscape of the globalized western classroom and discuss current pedagogical challenges in communication courses from the perspective of communication instructors.
\end{abstract}

Keywords: International students, communication, communication education, basic course, pedagogy 
As the movement toward international education continues, institutions must be proficient when reaching and teaching international students. As instructors, we should engage unique learning styles, address individual student needs, and take part in additional training to effectively reach international student learners. This imperative is especially pertinent in communication-related classes, like public speaking or composition. Throughout this reflection, we will address the globalized western communication classroom and discuss our perspectives on pedagogical challenges in communication courses and offer practical solutions.

\section{LITERATURE REVIEW}

The number of international students continues to steadily increase. Daller and Phelan (2013) believe that by 2020 a rise to seven million international students is expected worldwide. This number is astounding especially when compared to 3.7 million international students in 2011(Chau, 2011). The increase of international students brings with it a host of instructional dilemmas. In our experience, the issue is especially relevant in western-style communication courses where instructors are sometimes tasked with educating non-native English speakers.

Even though international students tend to be among the brightest and best from their own countries delivery (or communicationrelated) barriers are not uncommon (Russell, Rosenthal \& Thomson, 2009). Communication instruction, in U. S., established English as a primary classroom language and the foundation of communication subject-matter. The instruction for international students not familiar with Western communication skills training may present challenges. As the number of international students grows, it is important to address challenges unique to the communication classroom especially in general education curricula.

Our teaching experience and instructional styles vary greatly. Two of us are graduate students with minimal teaching experience and one of us is an Assistant Professor with extensive teaching experience at multiple universities. Two of us are domestic students while one of us is an international student who came to the U.S. to complete an American doctoral program. Despite our differences, one principle 
unities us, we recognize the importance of communication education and the necessity of reaching the unique learner.

Pedagogy and classroom experience are often unique to the individual instructor and each learner. It is hard to "generalize" a classroom context when each participant may not experience the same challenges. As a result, a reflection like this one is challenging as student groups may respond differently to our strategies. With that being said, we have experienced a variety of pedagogical challenges in the context of communication education. As a result, we have identified a variety of student learning barriers in the prototypical communication classroom of a "standard" American institution. Specifically, at least in terms of broader challenges, we discuss the construction of knowledge, student epistemologies, linguistic differences, and classroom expectations as pillars of the potentially confusing interaction between instructors and international students in the United States.

The pedagogical issues presented throughout this manuscript are important, but it is also necessary to have a working knowledge of the overall educational context and communication expectations of several US institutions. Communication skills are important for all academic, professional, and social experiences and, consequently, play a major role in a student's academic success (Simonds, Buckrop, Redmond, \& Quianthy, 2012). Often, to establish a general education spectrum, institutions will offer at least one basic communication course to all students at a university. The basic course traditionally focused almost exclusively on public speaking skill development. However, the content of the basic communication course has changed dramatically over time and progressed from public address to multimodal communication.

Students are typically expected to perform at high levels in three primary areas of communication: oral, written and visual. Instructors, who primarily have a "performance" bent (as communication is often exhibited through behavior) will grade and judge students based on multimodal (oral, written, visual) communication efficacy. Ultimately, we believe there is nothing "inherently wrong" with this principle. However, if students lack a true working knowledge of the English language and typical communication skills (in a western context this would include eye contact, intentional and message- 
reinforcing gestures, vocal inflection, etc.) then the ability of an instructor to analyze this student as proficient in knowledge and behavior may be impacted. In our opinion, it is hard to establish a sense of consistency in grading, reflection, and instructional strategy when students in a "western-style communication course" hail from various international contexts and utilize different communication norms. As such, this essay is our attempt to navigate the "big picture" issues, general challenges and barriers that may inhibit effective communication instruction of international audiences.

One challenge with the design and implementation of the basic communication course is the emphasis on western-style communication skills. While differences are present in other courses and disciplines, the specific behaviors and characteristics necessary for international students, especially non-native speakers, to succeed in a western-style communication course is an area of primary concern (Omar, 2014). Students and instructors must adapt in order to foster a successful instructional experience. Obviously, there may be other barriers in the typical communication course however, we believe three are primary: construction of knowledge, linguistic differences and classroom expectations.

It is important for communication instructors to first address constructive learning or the construction of knowledge. Carroll and Ryan (2005) believe that students do not learn from the 'telling of the teacher', but by taking the information, constructing and building it as a learner. This educational philosophy is highly dependent on schemas. Carroll and Ryan (2005) further state that schemas "mediate experiences and channel thinking by structuring the selection, retention, and use of information, summing up what we already know from previous experiences, interactions, and beliefs" ( $p$. 13). New experiences cause a modification of our schemas and as a result these schemas grow and eventually become rooted in our social and cultural contexts (Carroll \& Ryan, 2005). When international students visit a new cultural context their constructive learning may be harder to initiate because students must reorient their educational schemas.

The challenge of learner-based knowledge construction is often present in countries that insist on information transfer via manuscript recitation or lecture. In our experience this constitutes the 
instructional design of the communication course of the past. Today, many communication courses, especially courses where we serve as the instructor, are hands on and constantly interactive. For us, lecture is no longer the driving instructional strategy. This is difficult because international students, in some instances, are used to the instructor as "oracle". A constructivist environment, a climate that we try to encourage in our classrooms, may place more onus on the learner (rather than the instructor) to construct new meaning from subject matter. The instructor must implement constructive learning in the classroom in a way that international students can connect, add to, and build new educational schemas without making these same students feel uncomfortable.

Instructors have to be aware of different epistemologies international students bring that may eschew constructive learning. Cultures that view knowledge as transmitted through tradition may find it challenging to engage in constructive discourse. Olaniran (2009) proposes that societies identified as 'high context' and 'power distant' might not foster the building of community envisioned by western social constructivist thinking. He describes 'high context' culture as one where information is internalized within the individual and situation and not necessarily part of the social discourse (Olaniran, 2009). How does this manifest itself in a communication classroom that may emphasize discussion? If the individual learner and, as a result, individual learning, is separate from the community, discourse may be discouraged or not present which could limit the exploration of ideas.

Unlike 'high context' cultures, 'power distant' cultures recognize, or accept, the fact that power is not evenly distributed and thus behavior and interaction is guided along these power lines (Olaniran, 2009). This interactional pattern is also apparent in those individuals coming from more collectivist cultures where power distance can lead to a willingness to interact with peers (same power) compared to a reluctance to participate in a discussion lead by an instructor (high power).

Power distance changes interaction in the classroom. In Asian cultures, for example, the instructor is highly regarded (i.e. the oracle model). This often causes students from Asian countries to refrain from asking questions or sharing challenging ideas, a stark contrast 
from the Western style of teaching where students are expected and even graded on participation (Dresser, 2005). To combat this idea, we have added sections to our syllabi on the teacher-student power dynamic. If we view the syllabus as a communication document, the simple addition of a paragraph that encourages opinions that may be unique or controversial, can have a substantial impact. Additionally, students, especially international students, need to know that they are welcome to disagree with their peers or the instructor, as long as the disagreement is respectful.

Along with constructive learning, language barriers may inhibit learning for international students placed in a western communication classroom. When international students make mistakes in areas like language and sentence structure, organization, or shallow development, it reflects the difference in cultural backgrounds (Chapel \& Wang, 1998). Li (2007) argues that knowledge of the host culture's language is essential for all communication activities and successful cross-cultural adaptation. If non-native speakers cannot understand the language they may not construct knowledge in the classroom or communicate effectively during in activities and assignments and interactions with peers and instructors. As a result, taking notes, writing assignments, and asking questions all become challenging.

Communication courses serve the purpose of teaching students to value the discipline of communication, understand communication content, and practice communication skills effectively. Unfortunately, for communication instructors in the U.S., cultures value different types and styles of communication. In Asian and Middle Eastern cultures, for instance, silence is often a way of communicating. These same cultures value indirectness and social harmony. As a result, students from these areas will probably communicate according to their cultural norm. In a typical communication classroom at an American institution it is necessary for students to learn the value of direct language, use of words for expression, and how to display intercultural communication and it is equally important for instructors to have a working knowledge, and appreciation, of varying cultural norms (Adler, Rodman, \& du Pre, 2014). 
Finally, basic classroom expectations challenge the instructional domain. Anderson and Moore (1998) said that classroom environment most directly impacts international student learning. Expectations, like language or style preference, often vary from culture to culture. Surveys show a great amount of international students express concern over differences between school systems in the United States versus their home countries (Omar, 2014).

One area of classroom management, or classroom expectation, is punishment. Instructors of all experience levels, ourselves included, will, at some point, face disruption or a lack preparation for the lesson at hand, which often leads to some kind of punishment. Western cultures, especially American culture, are believed to be too lenient with discipline in schools. On the other hand, in Asia, the Middle East, and Latin America corporal punishment is acceptable (Dresser, 2005).

The way an instructor navigates punishment and student misbehaviors can reinforce student-instructor rapport or break down the instructor-student relationship. Some specific areas of concern in the communication classroom, especially in written and oral communication projects, are plagiarism and expectations of intellectual property. It is vital that faculty not conflate a misunderstanding of plagiarism with unethical behavior as this can create walls between the international student and faculty. SutherlandSmith (2005) argues that current ideas about plagiarism come from the Romantic concept of authorship and author as owner of text. Many international students do not hold to this view of authorial ownership (Pennycook, 1996). Some cultural communities see generated texts as the result of community efforts and thus the community holds ownership implicitly. We believe that some international students need help understanding the value of intellectual property and accurate documentation of resources.

The instructor-student relationship can also be challenging or confusing for international students as the parameters of the relationship may vary from culture to culture (Robinson, 1992). In the United States, equality is honored. In the West, instructors may be more informal and open in the classroom and to some international students this can create an environment that may seem devoid of formality (Robinson, 1992). 
Through this section we have addressed several general challenges. Even in the midst of the generality it is easy to see the need for pedagogically appropriate strategies that fulfill academic rigor and meet professional demands of graduates (Sachtleben, 2015).

International students vary in learning styles, cultural understanding, and language efficiency. As more students begin to study abroad, pedagogical philosophies must be improved in institutions that attract international students. Tsolidis (2012) believes the "cultural impact on pedagogy and the ways in which we understand teaching and learning are framed by time and place; in other words, pedagogy and curriculum, like all knowledges, are culturally-situated and as such are framed by social, political and historical context" (p. 103). We believe that in order to be effective instructors should remember the unique nature of all individual learners, especially international students.

Instructors can, and should, practically respond to the issues presented above. Arkoudis (2005) proposes internationalizing the curriculum and content, making lectures accessible, creating opportunities for small group participation, adopting an educational approach to plagiarism, supporting students in developing critical thinking skills, and explaining assignment expectations. These strategies are all relevant for any communication course or, for that matter, any college course.

In our classrooms, we try to utilize a variety of practices to enhance the communication comfort level of international students. One of our favored strategies is pair work (Sachtleben, 2015). Conversation training, "Think, Pair, Share", can be utilized in a communication course to enhance interpersonal communication skills training and establish a foundation for experiential communication behavior. Think, Pair, Share, which can allow international students the opportunity to practice conversational language, can also serve as a unique opportunity to encourage cultural competence (by allowing international students to share about their home country). Group dynamics and diversity can help group members learn various processes to handling issues and work while causing cultures to interact (Anderson \& Moore, 1998).

We have found that placing students in small group opportunities where the conversation can be culture specific will help build student- 
student rapport and will enhance communication skills. It is possible, however, that domestic students may be insensitive towards international students, especially if the language barrier is prevalent. The onus then is on the instructor to serve as a cultural guide. Asking questions that an international student would feel comfortable answering (like questions about cultural differences, family, etc.) may also erase challenges associated with group or pair conversation training.

Classroom activities and instructional strategies are important but assessment is also a critical component. We believe that assessment, especially midterm evaluations, can be a critical addition to a course with international students. A midterm evaluation, a formative assessment, presents international students with an anonymous forum to discuss their own unique challenges.

Additionally, in order to evaluate international students in a summative and developmental way, instructors must clearly communicate the expected procedures and outcomes while considering the potential language barrier (Anderson \& Moore, 1998). Attention must be paid to international student learning needs, abilities and weaknesses (Omar, 2014). Instruction, and grading, must remain consistent, but professors should present international students with the opportunity to succeed. For example, like native speaking American students, who routinely need assignments explained to them beyond the syllabus, international students should be given clear expectations and, like any course, clear rubrics. Explaining assignment expectations may entail additional meetings during office hours or unique explanations of the content and the assignment. We have all personally invited international students to visit our office during office hours instead of just offering a blanket invitation to the class as a whole. We have all found greater success using this method.

Finally, in the past, all of us have been tempted to grade international student papers or speeches more lenient, which should be avoided. With that being said, to harken back to our previous thought, we believe that if instructors meet with international students and provide one-on-one training and additional instruction, international students will be well prepared for the rigors of communication-based assignments. Accompanying international 
students to university writing or communication centers (where practice, repetition, and one-on-one training are emphasized) may also help prepare non-native speakers for speaking and writing expectations.

\section{DISCUSSION AND CONCLUSIONS}

We hope we did not position a western style of communication effectiveness as superior. Each culture has a traditional style of communicating and presenting cultural norms and these differences should be valued. Unfortunately, the typical communication instructor in United States institutions may struggle with making the subjectmatter relevant and applicable to a student with varying cultural communication norms.

The academic integrity of the classroom should never be questioned, international students should be expected to complete the same assignments, with the same standards, as domestic students, but universities would be remiss to not create environments of excellence that breed success rather than frustration. Universities must answer the call to be pedagogically sound and willing to invest in the training of instructors who will integrate creative classroom methods in an effort to reach internationals. International higher education is not a new concept, but as accessibility increases and as demand soars, we believe that those who are on the cutting edge of sound pedagogy will remain competitive, and effective.

\section{REFERENCES}

Adler, R., Rodman, G., \& Du Pre, A. (2014). Understanding human Communication $\left(12^{\text {th }}\right.$ ed.). New York, NY: Oxford University Press.

Anderson, M., \& Moore, D. (1998). Classroom globalization: An investigation of teaching methods to address the phenomenon of students from multiple national cultures in business school classrooms. Melbourne, Victoria: Faculty of Business and Economics, Monash University.

Arkoudis, S. (2005). Teaching international students: Strategies to 
enhance learning. Centre for the Study of Higher Education. Retrieved from http://www.cshe.unimelb.edu.au

Carroll, J., \& Ryan, J. (2005). Teaching international students:

Improving learning for all. London: Routledge.

Chau, A. (2011). OCED: International student number rises to 3.7 million. Retrieved from http://www.iu.qs.com

Daller, M. H., \& Phelan, D. (2013). Predicting international student study success. Applied Linguistics Review, 4(1), 173-193. doi:10.1515/applirev-2013-0008

Dresser, N. (2005). Multicultural manners. Hoboken, New Jersey: John Wiley \& Sons.

Fischer, K. (2012). U.S. college's global efforts fall short in areas like languages and faculty. Chronicle of Higher Education. Retrieved from http://chronicle.com/article/Colleges-Effortsto-Globalize/132661/

Li, D. (2007). Coping with linguistic challenges in UK higher education: The use of strategies by Chinese research students. Language Learning Journal, 35(2), 205-219.

Li, H., Fox, R., \& Almarza, D. J. (2007). Strangers in stranger lands: Language, learning, culture. International Journal of Progressive Education, 3(1), 1-44.

Olaniran, B.A. (2009). Culture, learning styles, and Web 2.0. Interactive Learning Environments, 17(4), 261-271.

Omar, M. M. (2014). Evaluating international students' perceptions of higher education performance based on four factors: Culture, language, pedagogy and university support (Order No. 1584852). Available from ProQuest Dissertations \& Theses Global. (1660540777). Retrieved from http://search.proquest.com/docview/1660540777?accountid=6 741

Pennycook, A. (1996). Borrowing other's words: Text, ownership, memory and plagiarism. TESOL Quarterly, 30(2), 201-230.

Russell, J., Rosenthal, D., \& Thomson, G. (2010). The international student experience: Three styles of adaptation. Higher Education, 60(2), 235-249. doi:10.1007/s10734-009-9297-7

Sachtleben, A. (2015). Pedagogy for the multilingual classroom: interpreting education. Translation \& Interpreting, 7(2), 5159. doi:10.12807/ti.107202.2015.a04 
Simonds, C. J., Buckrup, J., Redmond, M., \& Quianthy, D. H. (2012). Revised resolution on the role of communication in general education. Retrieved from http://www.natcom.org

Sutherland-Smith, W. (2005). The tangled web: Internet plagiarism

and international students' academic writing. Journal of Asian Pacific Communication, 15(1), 15-29.

Tsolidis, G. (2001). New cultures new classrooms: International education and the possibility of radical pedagogies. Pedagogy, Culture, and Society, 9(1), 97-110.

Heather Campbell, is a graduate student in the M.A. program at Bellarmine University. She is primarily interested in instructional communication. Email: hcampbell03@bellarmine.edu

Michael G. Strawser, $\mathrm{PhD}$, is a professor of communication at Bellarmine University. His research interests include instructional and organizational communication and he teachers a variety of courses including intercultural communication and communication ethics. Email: mstrawser@bellarmine.edu

Stephen George, M.A., is a PhD student at the University of North Texas. He is interested in contextualizing theological education and linguistics study. Email: stephenjgeorge@gmail.com

Manuscript submitted: September 9, 2015 Manuscript Revised: October 10, 2015 Accepted for publication: March 4, 2016 